\title{
A study on rational drugs prescribing in General out Patient Department (GOPD) BPKIHS, a tertiary care teaching University at Dharan, Eastern part of Nepal,
}

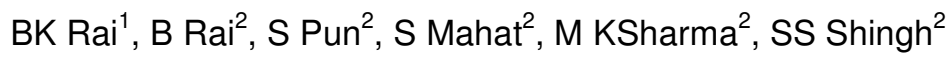 \\ Department of General Practice and Emergency Medicine ${ }^{1}$, MBBS $4^{\text {th }}$ year students ${ }^{2}$ \\ B.P. Koirala Institute of Health Sciences, Dharan, Nepal
}

\begin{abstract}
Background: A prescription is standard form that is used by doctors to prescribe medicines. A prescription done ideally include some demographic profile and detail instructions of what medicines should be given to whom, what formulations, how much doses, by which route, when, how frequently and for how long. The rational drugs prescribing and prescription writing is important in patient care. The incomplete prescription and irrational drugs would be harmful to patient. The $\mathrm{WHO}$ has defined rational use of medicines as requiring that "patients receive medications appropriate to their clinical needs, in doses that meet their own requirements for an adequate period of time at the lowest cost to them and their community." Assessment of prescription pattern helps in formulating prescribing policies of the institution. Objective: The study aims to finding out the prescription writing skill on the base rational drug prescribing in GOPD, BPKIHS. Method: A cross sectional study was conducted in GOPD, BPKIHS, in two week period from 13th July 2012 to 27 th July 2012. A semi structured questionnaire was used to document difficult variables and interviewing the patients. A total number of 100 prescriptions were analyzed and the same number determined. Results: The number of male and female patients was 57 and 43 respectively. The minimum age recorded was 15 and maximum age 85 . The mean age was $38.64 \pm 18.702$ (range 15-85 years). General physical examination and systemic examination were mentioned in 63 and $72 \%$ cases respectively. Likewise $91 \%$ cases were advised for laboratory investigations. Provisional and final diagnoses were mentioned in $49 \%$ and 54\% respectively. Forty-six patients were treated on empirical basis. Six percent of patients were prescribed more 5 items, 18\% patients. 4 items and $36 \%$ patients were prescribed 3 items of drugs. Only 31\% patients were prescribed 2 items of drugs that would

Address for correspondence

Dr. Bijendra Kumar Rai

Additional Professor

Department of GP and EM

B.P. Koirala Institute of Health Sciences, Dharan

Email: bijen001@gmail.com

meet the criteria of World Health Organization guide to prescription. Common side effects of prescribed drugs were not mentioned in $84 \$$ patients. Drug prescribing in the GOPD of BPKIHS is not as per
\end{abstract}


the WHO guidelines with many missing important details. Seventeen percent of patients had no recall, only $29 \%$ of patients had excellent recall for how to take prescribed medicines. In $51 \%$ patients special advises related with prescribed drugs were provided. The follow up visit was mentioned in $78 \%$ patients. Seventy percent patients did not known the name of treating doctors and $58 \%$ patients were happy with the doctor's consultation. Conclusion: A majority of the doctors were not able to correctly define rational drugs prescribing and there is missing many important details in prescription writing. Therefore an educational intervention regarding the rational drug prescribing and prescription writing skills should be carried out in all doctors working in GOPD.

Keywords: Doctors, education, prescription, rational drugs prescribing

\section{Introduction}

"Hippocrates' advice still holds today. Prescribe only where necessary, and consider benefits versus risks. Involve the patient in decisions about their care and respect patient autonomy."

A prescription is a standard form that is used by doctors to prescribe medicines. A prescription includes detail instructions of what medicines should be given to whom, what formulations, how much doses, by which route, when, how frequently and for how long. ${ }^{1}$ In every prescription patient's some characteristics demographic need to be included. The demographic factors such as low socioeconomic status and low level of education have been associated with lower regimen adherence. ${ }^{2}$

The prescription includes not only the name of a patient but also includes the name of the treating doctor, the date on which the prescription is written. After completing these formations further step is followed by general physical examination, systemic examination, needful investigations, provisional diagnosis and/or final diagnosis, lists of prescribed medicines and validity of prescription.

Similarly, the prescription is symbol of rational use of medicines. The WHO has defined rational use of medicines as requiring that "Patients receive medications appropriate to their clinical needs, in doses that meet their own requirements for an adequate period of time at the lowest cost to them and their community." 3 The rational use of medicines has many components, all of which must be in place before we can say that a drug has been rationally used. Rational use of drugs should ensure: correct drug, appropriate indication' appropriate drug considering efficacy, safety, suitability for the patient, and cost, appropriate dosage, administration, 
duration, no contraindications, correct dispensing, including appropriate information for patients and patient adherence to treatment.

Promotion of rational drug use improves prescribing habits: When many drugs are prescribed for a patient, verify that they are absolutely necessary for treating the diagnosed condition. Use standard treatment schemes for common illnesses. Verify a second time that the drug is appropriate before dispensing it to the patient ${ }^{3}$.

Good prescribing habits imply the use of a limited number of drugs of which the doctor has a good knowledge. The risk of inappropriate prescribing is higher among doctors who prescribe many different drugs. However the prescribing habits of an individual doctor is quite stable and changes usually occurs slowly as a result of various influences, including scientific papers, specialist recommendations, meetings, colleagues, patients, and drug companies. ${ }^{4}$

The minimum information that should be given to the patient include effect of the drug, side effects, instruction of the warnings, future consultations and confirmation of clear understanding.

An incomplete prescription and the use of drugs which are considered irrational would be harmful to patient and bad prescribing habits lead to ineffective and unsafe treatment, exacerbation or prolongation of illness, distress and harm to the patient and causes higher costs.

\section{Methods}

The study was a cross-sectional survey of all prescriptions received from the patients over two week's period from 13th July 2012 to 27th July 2012.

The inclusion criteria were: new patients attending in GOPD, the age of 15 or above, of both gender, patients agree to give consent to participate in the study. The exclusion criteria were old patient (age >85), patients with hearing and speak disability, the referred cases from outside, uncooperative, unwilling to participate in the study and patients denying consent.

The layout of the prescriptions was assessed on the basis of the following details: doctor's name, address, phone number, qualifications, registration number and signature, patient details: patient's name and address and date of consultation. The content of prescription was assessed on the basis of drugs used i.e. number, duration of therapy, type of medications, whether generic names or brand names. To remove bias, all forms had the same clinical questions to maintain the standard assessment criterion.

The working hours defined as from 10 to $12 \mathrm{pm}$ on Sunday to Friday from 13 July to 27 July 2012 except holiday. The prescriptions were collected on random basis. The patients 
coming outside the consultation room after consultation were involved and the information of the prescription was collected. Those patients who fit to inclusion criteria were randomly selected. The detail of the study was explained to the each patient. The verbal consent was taken. The semistructured questionnaire sheet was filled up by interviewers. The first segment of the questionnaire was related to the demographic profile patient's age and sex, address, date, occupation, economic status and education status.

The second segment of the questioner's sheet was the layout of the prescription details i.e. general examination, systemic examination, provisional diagnosis, investigations, final diagnosis numbers of drugs prescribed, drugs side effect, specific advices, follow up, doctor's name, signature and happy with consultation were included. None of the doctors were informed about the prescription writing skills assessment until the day and date of survey. Data was analyzed using SPSS20.

\section{Results}

Ethical clearance was taken from Institution Review Committee of BPKIHS. The total percent were 100.

The mean age was $38.64 \pm 18.70$ with the age range of 15-85 years old.
Table 1:

\begin{tabular}{|l|l|l|}
\hline & Frequency & Percent \\
\hline Gender & & \\
Male & 43 & 43 \\
Female & 57 & 57 \\
Total & 100 & 100 \\
\hline Age & & \\
$<30$ & 14 & 14 \\
20-40 & 46 & 46 \\
$40-60$ & 22 & 22 \\
60+ & 18 & 18 \\
Total & 100 & 100 \\
\hline District & & \\
Bhojpur & 3 & 3 \\
Dhankuta & 3 & 3 \\
Illam & 2 & 2 \\
Janakpur & 1 & 1 \\
Sarlahi & 1 & 1 \\
Jhaoa & 11 & 11 \\
Khotang & 1 & 1 \\
Kathmandu & 1 & 1 \\
Morang & 9 & 9 \\
Saptari & 5 & 5 \\
Shankhusabha & 1 & 1 \\
Siraha & 1 & 1 \\
Sunsari & 58 & 58 \\
Terathum & 1 & 1 \\
Udayapur & 1 & 1 \\
Taplejung & 1 & 1 \\
Total & 100 & 100 \\
\hline Education & \\
Literate & 70 & 70 \\
Illiterate & 30 & 30 \\
\hline
\end{tabular}




\begin{tabular}{|l|l|l|}
\hline Total & 100 & 100 \\
\hline Economic & & \\
Status & 13 & 13 \\
Low & 84 & 84 \\
Middle & 3 & 3 \\
Higher & 100 & 100 \\
Total & & \\
\hline Occupation & & \\
Housewife & 44 & 44 \\
Farmer & 20 & 20 \\
Service holder & 9 & 9 \\
\hline
\end{tabular}

\begin{tabular}{|l|l|l|}
\hline $\begin{array}{l}\text { Others } \\
\text { Total }\end{array}$ & 27 & 27 \\
100 & 100 \\
\hline $\begin{array}{l}\text { Provisional } \\
\text { diagnosis }\end{array}$ & 49 & 49 \\
Yes & 51 & 51 \\
No & 100 & 100 \\
Total & & \\
\hline Final diagnosis & & \\
Yes & 46 & 46 \\
No & 54 & 54 \\
Total & 100 & 100 \\
\hline
\end{tabular}

\section{Table 2:}

\begin{tabular}{|l|l|l|}
\hline & Frequency & Percent \\
\hline General examination & & \\
Yes & 63 & 63 \\
No & 37 & 37 \\
Total & 100 & 100 \\
\hline Systemic examination & & \\
Yes & 72 & 72 \\
No & 29 & 28 \\
Total & 100 & 100 \\
\hline Investigation & & \\
Yes & 91 & 91 \\
No & 9 & 9 \\
total & 100 & 100 \\
\hline & & \\
\hline
\end{tabular}

\section{Discussion}

This is a descriptive cross-sectional hospital GOPD based study. This study was an attempt to find the existing pattern of prescription writing in GOPD. The prescriptions collected on random basis after consultation. The semi structure questioners' form filled up with the help of prescription. The 100 samples fulfilled within 2 weeks period from $13^{\text {th }}$ July to $27^{\text {th }}$ July 2012 . 
The numbers of male and female patient were found $57 \%$ and $43 \%$ respectively. The minimum age was recorded 15 and maximum age of 85 . The mean age was found 38.64 and standard deviation of 18.702. The highest percentage of patients came under the age group of $20-40$ (46\%) followed by 40 to 60 (22\%). The maximum number of patients came from Sunsari. (58\%) and followed by Jhapa $11 \%$ patients. By occupation it was found $44 \%$ patients were belonging to household and $22 \%$ patients were farmer. The middle class families were $84 \%$ and lower class were $13 \%$ and $70 \%$ patients were literate $30 \%$ patients were illiterate.

In $63 \%$ and $72 \%$ patients have mentioned about general physical examination and systemic examination respectively. The $91 \%$ patients were advised for laboratory investigations. It was found that $49 \%$ patients have been mentioned about provisional diagnosis and $54 \%$ patients have final diagnosis. The most interesting part of the study was found $46 \%$ cases were treated on empirical basis. It was found that in 6 patients were prescribed more 5 items of various drugs, $18 \%$ patients were prescribed 4 items of drugs. Similarly $36 \%$ patients were prescribed 3 items of drugs. Only 31\% patients were prescribed 2 items of drugs that would meet the criteria of world Health Organization a guide to prescription "Average number of drug prescribe should not be more than 2 items of drugs". It was found that $84 \%$ patients were not making aware about drugs side effects of prescribed drugs. $17 \%$ patients have no recall what the doctor said about drugs how to take, how many time per day, when to take and how long to take. Similarly $23 \%$ patients were found poor recall, average recall $31 \%$ and excellent recall was found $29 \%$ for how to take prescribed medicines.

In $51 \%$ patients had provided special advises related with prescribed drugs. The follow up visit was mentioned in $78 \%$ patients. The another interesting part of the study was $70 \%$ patients did not known the name of doctors and only $58 \%$ patients were happy with the doctor's consultation.

\section{Conclusion}

A majority of the doctors were not able to correctly define rational drugs prescribing and there is missing of many important details in prescription writing. Therefore an educational intervention regarding the rational drug prescribing and prescription writing skills should be carried out in all doctors working in GOPD. The MBBS students who were actively involved in this research as a coinvestigator had got sufficient amount of exposure with patients and had a golden opportunity to know the importance of rational of prescribing drugs and prescription writing skill. 


\section{References}

1. Aronson JK. Medication errors: Definitions classifications. $\mathrm{Br} \mathrm{J}$ Clin Pharmacol 2009; 67(6):599604.

2. $A M$, Jacobson $A M$, Anderson BJ, Cox $D$, Fisher L, Lustman $P$, Rubin $R$, Wysocki T: Psychosocial therapies in diabetes: report of the Psychosocial Therapies Working Group. Diabetes Care. 2001;24: 1286-1292.

3. The use of essential drugs. Sixth report of the WHO Expert Committee. Geneva, World Health Organization, 1995 (WHO Technical Report Series, No. 850.

4. Bjerrum L, Larsen J, Sondergaard J. Drug prescription patterns in general practice. Extent, problems and possibilities of improvement. 2002; 4: 164(45):5273-7.

5. T. P. G. M. de Vries1, R. H. Henning1, H. V. Hogerzeil2, D. A. Fresle2, Guide to good prescription, a practical manual, who action program on essential drugs Geneva, chapter-9, step -4,Page No 66.72, 74.

6. Pollock M, Bazaldua OV, Dobbie AE Appropriate prescribing of medications: an eight-step approach. Am Fam Physician. 2007; 15: 75(2):231-6.

7. Garjón Parra FJ [Prescribing drugs to patients receiving out-patient care]. An Sist Sanit Navar. 2009; 32(1):11-21.
8. Anuja A Pandey, Subhash B Thakre, and Prakash $\mathrm{R}$ Bhatkule, Prescription Analysis of Pediatric Outpatient Practice in Nagpur City. Indian J Community Med. 2010; 35(1): 70-73.

9. Jgbiks Tamuno, Prescription pattern of clinicians in private health facilities in Kano, Northwestern Nigeria. Asian Pacific Journal of Tropical Disease. 2011; 235-236.

10. Alam, K., P. Mishra, M. Prabhu, P.R. Shankar, S. Palaian, R.B. Bhandari and D.A. Bista, 2006. Study on rational drug prescribing and dispensing in outpatients in a tertiary care teaching hospital of Western Nepal. Kathmandu Univ. Med. J., 4: 436-443.

11. T.M. Vijayakumar, D. Sathyavati, T. Subhashini, S. Grandhi and M.D. Dhanaraju, 2011. Assessment of Prescribing Trends and Rationality of Drug Prescribing. International Journal of Pharmacology, 7: 140-143.

12. Shapna Sultana, Kaiser Hamid, Kazi et al Patient's Prescription: A Prescription Survey Study from Various Hospitals of Bangladesh. European Journal of Scientific Research. 2010; 40(4): 500505.

13. Ranjeeta Kumari, MZ Idris et al..Assessment of prescription pattern at the public health facilities of Lucknow 
district.Indian Journal of Pharmacology, 0253-7613 40: 243-247.

14. Haynes RB, Yao X, Degani A, Kripalani $S$, Garg A, McDonald HP. Interventions to enhance medication adherence Cochrane Database Syst Rev. 2005;(4):CD000011.

15. Teichman PG, Caffee AE. Prescription writing to maximize patient safety. Fam Pract Manag. 2002; 9:27-30.

16. Pilot $F$, Standridge JB, Swagerty D. Caring for the elderly: An American Family Physician monograph. Leawood, Kan.: American Academy of Family Physicians, 2005.

17. Rochon PA, Gurwitz JH. Optimising drug treatment for elderly people: the prescribing cascade. BMJ. 1997; 315:1096-9.

18. Piette JD, Heisle M, Wagner TH. Costrelated medication underuse: do patients with chronic illnesses tell their doctors? Arch Intern Med. 2004; 164:1749-55.

19. Richards D; The problems and perils of prescription medicines. Clin Med 2003; 3:476-8.

20. Aronson JK, Henderson G, Webb DJ, Rawlins MD. A prescription for better prescribing. BMJ 2006; 333:459-60.

21. Cockburn J, Pit S. Prescribing behavior in clinical practice: Patients Expectations and doctors perceptions of Patients' expectations: A questionnaire study. BMJ 1997; 315: 520-3.

22. Grahame-Smith DG, Aronson JK, editors. Oxford textbook of clinical pharmacology and drug therapy. 3rd Ed. New York: Oxford University Press; 2002; 173-88.

23. Teutsch C. Patient-doctor communication. Med Clin North Am. 2003; 87(5):1115-45. 